\title{
HERBERT DIESS
}

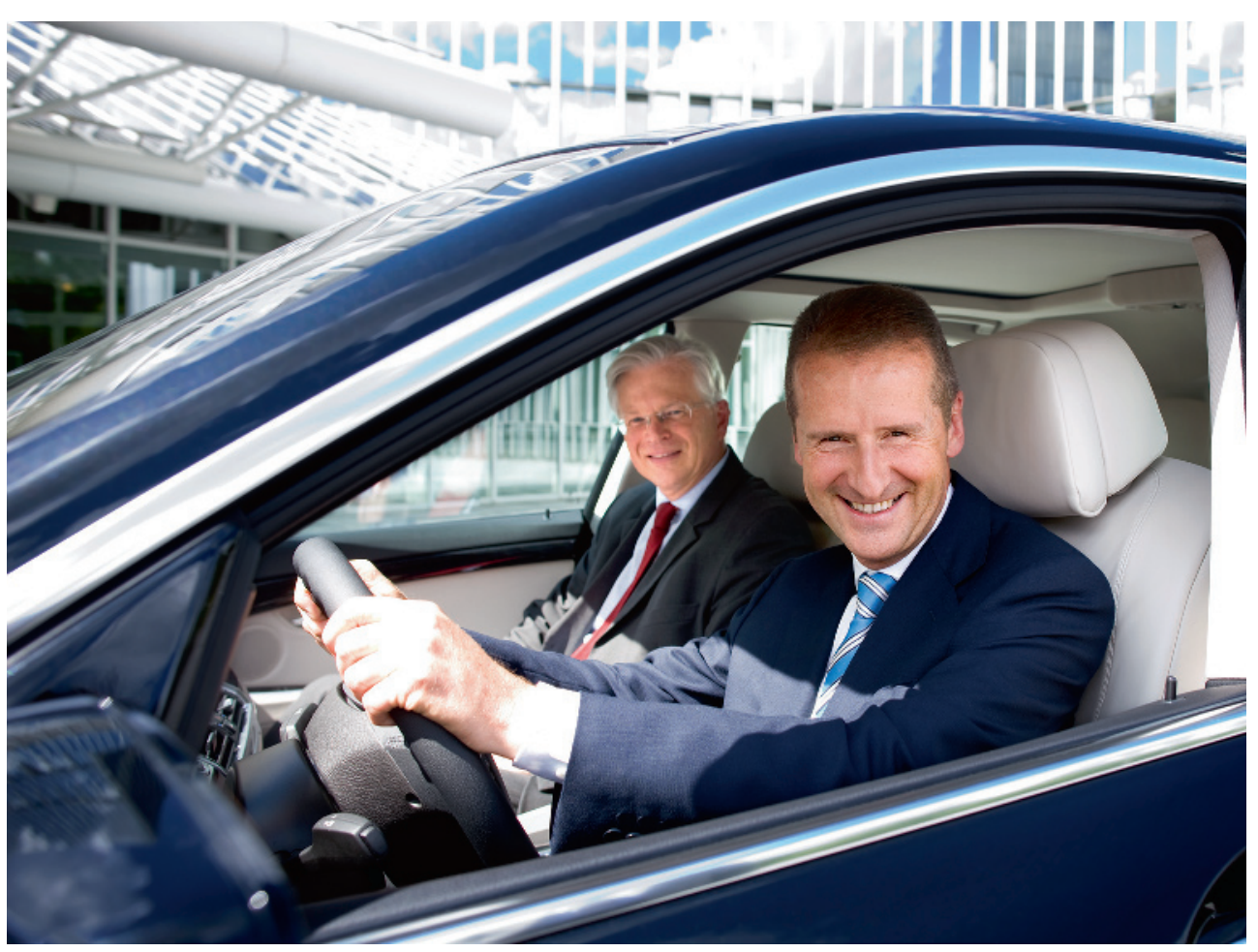

Lenkpräzision und überzeugende Fahrdynamik: Die Marken-DNA der BMW Group zu perfektionieren, ist oberstes Ziel von Dr.-Ing. Herbert Diess, Entwicklungsvorstand bei der BMW AG. Seit 1. April 2012 ist Diess „Chefentwickler" und Vorgesetzter der rund 10.000 Mitarbeiter des BMW Forschungs- und Innovationszentrums. Besonders in den Bereichen Elektromobilität und Leichtbau will er Impulse setzen.

BILD @ Toby Binder

\section{„TRAUMJOB ENTWICKLUNGSVORSTAND“}

„Freude am Fahren“, das ist der Markenclaim von BMW.

Dr.-Ing. Herbert Diess hat sie verinnerlicht. Cheffahrer, wie bei vielen Vorständen üblich? Fehlanzeige. Unser Chef fährt selbst, wie man hört.

Seit April 2012 ist Herbert Diess Vorstand der BMW AG für Entwicklung. Vorher war Diess viereinhalb Jahre als Vorstand für den Einkauf und das Lieferantennetzwerk zuständig, zum 1. April 2012 tauschte er diese Position mit Dr.-Ing. Klaus Draeger, dem bisherigen Entwicklungsvorstand.

Herbert Diess, Jahrgang 1958, wurde in München geboren. Dort studierte er an der Technischen Universität Maschinenbau. Nach seiner Promotion im Bereich Fertigungstechnik führte ihn sein Weg 1990 zur Robert Bosch GmbH. Nach mehreren Karriereschritten übernahm Diess die Leitung des Bosch-Werks im spanischen Treto. 1996 wechselte er zur BMW AG: Leiter Prozessberatung, Leiter der englischen Werke Birmingham und Oxford und die Leitung von BMW Motorrad waren die Karrierestufen vor der Übernahme der Vorstandsaufgabe „Einkauf“.

\section{„CFK UND ELEKTROMOBILITÄT“}

Traumjob Entwicklungsvorstand? Diese Frage beantwortet der Vater dreier Kinder nach kurzem Überlegen klar mit Ja! „Entwicklungschef bei BMW ist für mich die attraktivste Position in der gesamten Branche“, meint er.
Das Produkt steht für Diess dabei klar im Vordergrund. Differenziert wird über Innovation und Qualität. Kein Wunder, dass für ihn CFK und Elektromobilität die wettbewerbsentscheidenden Zukunftsentwicklungen sind. BMW hat sich frühzeitig auf CFK als Zukunftswerkstoff festgelegt. „Hier haben wir einen Wettbewerbsvorteil erarbeitet, der es uns erlaubt, die konsequenteren Elektromobile zu entwickeln und die konsequenteren Plug-in-Hybride auf den Markt zu bringen“, sagt er.

Im Bereich Elektromobilität und bei der gemeinsamen Entwicklung der nächsten Batteriezellengeneration mit Toyota sieht Diess das Unternehmen gut aufgestellt. „In fünf bis sieben Jahren werden wir einen Technologiesprung sehen. Neue Elektrochemie und neue Fertigungsverfahren werden Gewicht und Kosten der Zellen senken, und die Speicherfähigkeit von Batterien wird weiter steigen“, glaubt er.

\section{„FREUDE AM FAHREN“}

Diess ist begeisterter Motorradfahrer und leidenschaftlicher Autofahrer. Er erzählt genussvoll von einer Zeitenjagd in Elektrokarts - und auf dem Unternehmensgelände fährt er Elektroroller. Der steht hier in seinem Büro im Forschungs- und Innovationszentrums (FIZ). „Mit dem fahre ich zu meinem Kollegen Draeger, das geht auf dem weiträumigen Werksgelände schneller und macht Spaß“. Freude am Fahren eben! 